\title{
Current Situations and Challenges Concerning Sexual Health among Unmarried Couples Composed of a Mix of Japanese, South Korean Nationals, and Ethnic Koreans Born in Japan (Zainichi): A Qualitative Study
}

\author{
Chie Koh ${ }^{*}$, Hiroya Matsuo² \\ ${ }^{1}$ Graduate School of Nursing, Osaka Prefecture University, Osaka, Japan \\ ${ }^{2}$ Graduate School of Health Sciences, Kobe University, Kobe, Japan \\ Email: *tsubaki@nursing.osakafu-u.ac.jp
}

How to cite this paper: Koh, C. and Matsuo, H. (2017) Current Situations and Challenges Concerning Sexual Health among Unmarried Couples Composed of a Mix of Japanese, South Korean Nationals, and Ethnic Koreans Born in Japan (Zainichi): A Qualitative Study. Health, 9, 14-24.

http://dx.doi.org/10.4236/health.2017.91002

Received: November 26, 2016

Accepted: December 27, 2016

Published: December 30, 2016

Copyright $\odot 2017$ by authors and Scientific Research Publishing Inc. This work is licensed under the Creative Commons Attribution International License (CC BY 4.0).

http://creativecommons.org/licenses/by/4.0/

\begin{abstract}
South Korean nationals are heavily represented in Japan's foreign population, making up around $20 \%$ of all foreign residents in the country. Koreans in Japan can be viewed in two groups: Korean nationals who work or study in Japan, and those of Korean ancestry who were born in Japan or otherwise have historical reasons for residency (commonly called zainichi). There are certain differences seen in gender roles and Confucianism-based traditional culture among Japanese, South Korean nationals, and zainichi. This qualitative study examined consciousness and attitudes about marriage, family planning, and work-life balance in unmarried couples among these three groups. Semistructured interviews were conducted with five unmarried couples comprising two members from the above three groups (age range: 20 - 35 years), residing in the Kinki region of western Japan. Twelve categories, 25 subcategories, and 79 codes were extracted from 636 contexts. Values regarding sexual health were analyzed from four viewpoints: marriage, family planning, work-life balance, and sexual concerns. The results showed that the couples thought positively about marriage and family planning, while they had several sources of anxiety related to Confucian values and problems stemming from their different nationalities/roots. It is possible that gender roles and Confucian beliefs affect their sexual health. The study underscores that health professionals should provide pertinent knowledge and skills about family planning and child rearing, as well as premarital sexual health counselling, for unmarried couples composed of Japanese, South Korean nationals, and zainichi.
\end{abstract}




\section{Keywords}

Confucianism, Sexual Health, Unmarried Couples, Qualitative Study

\section{Introduction}

The number of registered foreign residents in Japan has continued to increase, and stood at 2,307,388 as of 2016 [1], accounting for $1.82 \%$ of the overall Japanese population [2]. Among them, South Korean nationals number 456,917, or approximately $20 \%$ of all foreign residents in the country. The Korean population in Japan can be viewed as two groups: those who work or study in Japan and those of Korean ancestry who were born in Japan or otherwise have historical reasons for residency (commonly referred to in Japanese as zainichi). Among this population mix, there is a considerable number of marriages between Japanese, South Korean nationals, and zainichi.

Japan and South Korea have similar geographic and historical backgrounds, and Confucianism has a strong influence in both. They also share similar attitudes toward sex, as seen in low cohabitation rates, tendency to discriminate against unmarried mothers [3], declining birth rates [3], increasing ages for first marriages and childbirth [3] [4], and increasing instances of pregnancy being the primary motivator for marriage [5] [6]. However, among Japanese, South Korean nationals, and zainichi, there are some differences in gender roles and traditional culture based on Confucianism. Zainichi Korean society has strong traditional values based on Confucianism, such as a paternal attitude and perceptions of gender roles. A study found that zainichi youth, compared with Japanese or South Koreans, maintain stronger values of this type [7]. Confucian values could possibly influence sexual behavior or health in couples composed of a mix of Japanese, South Korean nationals, and zainichi. To the best of our knowledge, no reports have demonstrated whether gender roles or Confucianism-based traditional values affect sexual behavior or health in such couples.

We therefore examined consciousness and attitudes regarding marriage, family planning, and work-life balance in unmarried couples of such composition. We used semi-structured interviews, as we sought to determine whether gender roles or Confucianism-based traditional values affect these couples' sexual health.

\section{Methods}

\subsection{Subjects}

The study participants were five unmarried couples representing pairings of Japanese and South Korean, Japanese and zainichi, and zainichi and South Korean. All were aged 20 - 35 and residing in the Kinki region of western Japan. The initial couple enrolled in the study was introduced via a member of a nationwide zainichi Koreans' organization. The other four couples were recruited by snowball sampling method. Informed consent was acquired from all partici- 
pants before the study began.

\subsection{Methods}

\subsubsection{Interview}

This was a qualitative descriptive study using semi-structured interviews. The interview format consisted of the following topics and questions: 1) Characteristics (age, nationality/background, occupation, and relationship period); 2) Marriage (Do you want to get married? When and/or why do you want to get married? Do you have any concerns about marriage?); 3) Family planning (Do you want to have a child? When and/or why do you want to have a child? How many children do you want to have? Which sex children do you want?); 4) Work-life balance (Do you want to continue to work after marriage? [female], How do you feel about your wife continuing work after marriage? [male]); 5) Concerns about sexuality (How do you feel about marriages because of pregnancy? How do you feel about marriage at a later age and the declining birthrate?) (Table 1).

The interview was conducted for each individual participant between July 2015 and March 2016. The mean time of interviews was 25 minutes 38 seconds (range: 14:59 to 36:42). All interviews were recorded using an electronic recorder

Table 1. Interview guide.

1. Characteristics

- age

- nationality /background

- occupation

- relationship period

2. Marriage

- Do you want to get married?

- When do you want to get married?

- Why do you want to get married?

- Do you have any concerns about marriage?

3. Family planning

- Do you want to have a child?

- When do you want to have a child?

- Why do you want to have a child?

- How many children do you want to have?

- Which sex children do you want?

4. Work-life balance

- Do you want to continue to work after marriage? [female]

- How do you feel about your wife continuing work after marriage? [male]

5. Concerns about sexuality

- How do you feel about marriage because of pregnancy?

- How do you feel about marriage at a later age and the declining birthrate? 
with the respondents' permission, and were transcribed. Interviews were conducted in Japanese or Korean as per the interviewee's preference.

\subsubsection{Data Analysis}

Transcriptions were coded to identify elements of each participant's values about sexual health. All codes were examined and compared for similarities or differences. Codes were then sorted into subcategories and categories using the KJ method [8]. Data analysis was performed by the first author independently and then discussed with two health professionals. Confirmability was obtained through discussions held with the second author.

\subsubsection{Ethical Consideration}

This study was approved by the Ethical Committee of Osaka Prefecture University Graduate School of Nursing. All participants provided written informed consent prior to participation.

\section{Results}

\subsection{Participants' Characteristics}

Mean age was 28.0 years for women and 27.8 years for men. The mean length of the relationships was 27.8 months (Table 2).

\subsection{Values Regarding Sexual Health in the Couples}

A total of 636 contexts of values regarding sexuality among the couples were extrapolated from the transcription. From these contexts, 12 categories, $25 \mathrm{sub}$ categories, and 79 codes were extracted, and the values regarding sexual health were analyzed from four viewpoints: marriage, family planning, work-life balance, and sexual concerns (Table 3). From this point, we described category, subcategory, code, and person's narrative as category, [subcategory], <code>, and "person's narrative".

Table 2. Characteristics.

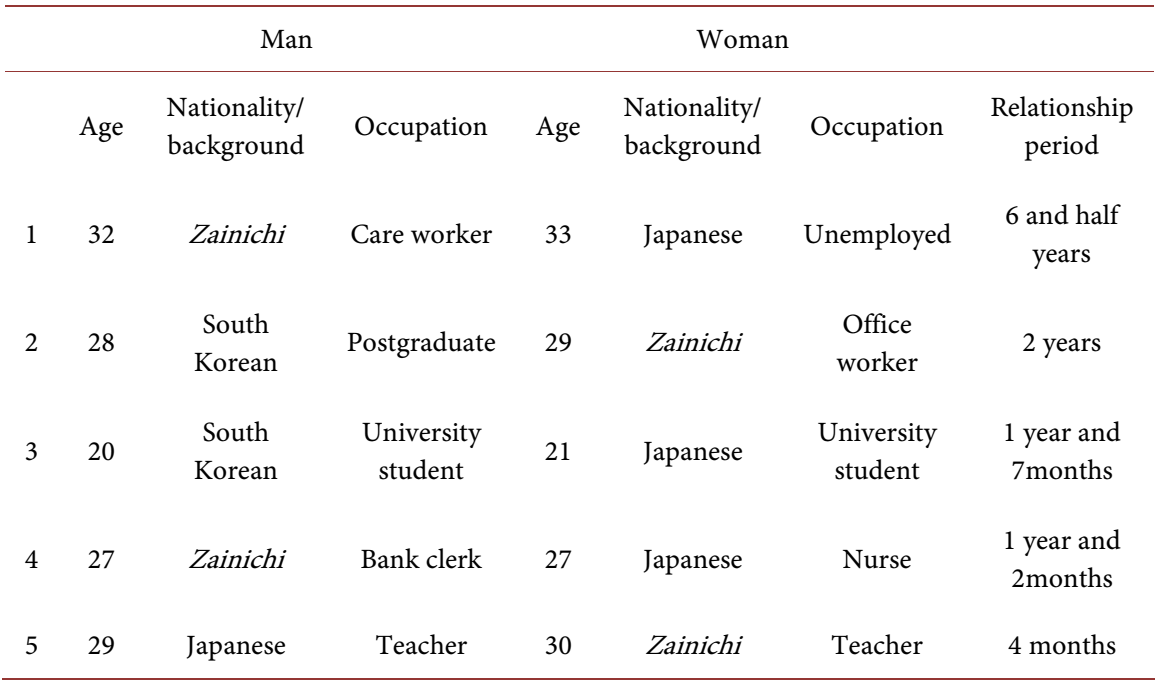


Table 3. The values on sexual health in the couples.

\begin{tabular}{|c|c|}
\hline Subcategory & Category \\
\hline \multicolumn{2}{|l|}{ They have a reason why they want to get married } \\
\hline They have a certain time when they want to get married & Positive feeling toward marriage \\
\hline \multicolumn{2}{|l|}{ They do not have a definite reason or time } \\
\hline I do not think that marriage is necessary & Passive feeling toward marriage \\
\hline \multicolumn{2}{|l|}{ Anxiety about being inexperienced } \\
\hline Anxiety about the future & Anxiety about marriage \\
\hline \multicolumn{2}{|l|}{ Anxiety about nationality and background } \\
\hline $\begin{array}{l}\text { Disadvantage of different nationality and background } \\
\text { Advantage of different nationality and background }\end{array}$ & $\begin{array}{l}\text { Feelings about different } \\
\text { nationality and background }\end{array}$ \\
\hline They want to have a child after their marriage & Appropriate age or time for \\
\hline They have a reason for having a child & childbirth \\
\hline \multicolumn{2}{|l|}{ Anxiety about raising their child } \\
\hline \multicolumn{2}{|l|}{ Anxiety over whether they can make a new family } \\
\hline $\begin{array}{c}\text { Worry about a child who has a different nationality and } \\
\text { background }\end{array}$ & $\begin{array}{l}\text { Anxiety about forming a new } \\
\text { family }\end{array}$ \\
\hline \multicolumn{2}{|l|}{ They do not have any obvious anxiety } \\
\hline $\begin{array}{l}\text { They want to have a few children } \\
\text { Thinking about child's sex }\end{array}$ & $\begin{array}{l}\text { Desire for a certain number and } \\
\text { sex of children }\end{array}$ \\
\hline $\begin{array}{l}\text { Desire to continuation of work } \\
\text { Various styles of work }\end{array}$ & $\begin{array}{l}\text { Continuation of work after } \\
\text { marriage and childbirth }\end{array}$ \\
\hline $\begin{array}{l}\text { They want to concentrate on childrearing } \\
\text { when their child is young }\end{array}$ & $\begin{array}{l}\text { Possibility to stop working for a } \\
\text { period after marriage and }\end{array}$ \\
\hline They will consult with their partner and decide & childbirth \\
\hline $\begin{array}{l}\text { They only think negatively } \\
\text { Getting married because of pregnancy can be challenging }\end{array}$ & $\begin{array}{l}\text { Feelings about pregnancy as a } \\
\text { reason for early marriage }\end{array}$ \\
\hline Thinking about actual social phenomena & $\begin{array}{c}\text { Feelings about declining birth } \\
\text { rate and increase of marriages at } \\
\text { a later age }\end{array}$ \\
\hline
\end{tabular}

\subsubsection{Marriage}

Four categories were highlighted from among nine subcategories classified. Almost all participants had a Positive feeling toward marriage, but one man had Passive feeling toward marriage. Almost all participants had Anxiety about marriage. Moreover, Feelings about different nationality and background were extracted.

\section{1) Positive feeling toward marriage}

This category consisted of three subcategories: [They have a reason why they want to get married], [They have a certain time when they want to get married], and [They do not have a definite reason or time]. Among participant comments were: "I want to have a child, so I want to get married." (Woman 1). And one man said, "It is better for a woman to give birth at an appropriate age." (Man 1). 


\section{2) Passive feeling toward marriage}

This category consisted of one subcategory: [I do not think that marriage is necessary]. All female participants wanted to get married, but this man absolutely did not. He said specifically, "I do not think we have to get married." (Man 2).

\section{3) Anxiety about marriage}

This category consisted of three subcategories: [Anxiety about being inexperienced], [Anxiety about the future], and [Anxiety about nationality and background]. [Anxiety about being inexperienced] consisted of three codes; $<$ Finances $>$, $<$ Matching of opinions with the partner $>$, and $<$ Responsibility for the family>. One woman spoke about [Anxiety about the future]; "He plans to live in Japan for a long time, but this isn't definite." (Woman 2). [Anxiety about nationality and background] consisted of three codes: $<$ Anxiety due to past experiences $>$, $<$ Worry owing to nationality and background $>$, and $<$ Anxiety about obtaining parents' permission $>$. One woman said, "Because his family is unusual as zainichi Korean, I don't know what they think about me, a Japanese." (Wo$\operatorname{man} 1)$.

\section{4) Feelings about different nationality and background}

This category consisted of two subcategories: [Disadvantage of different nationality and background] and [Advantage of different nationality and background]. Women spoke about [Disadvantage of different nationality and background]; "I think we have various problems regarding marriage. If he were Japanese, I don't think we would have these problems." (Woman 1). "We need to occasionally go to South Korea to see to his parents, and therefore use extra money and labor." ( Woman 2).

\subsubsection{Family Planning}

Three categories were highlighted from eight subcategories classified. Participants thought about Appropriate age or time for childbirth and Anxiety about forming a new family. They also had Desire for a certain number and sex of children.

1) Appropriate age or time for childbirth

This category consisted of two subcategories: [They want to have a child after their marriage] and [They have a reason for having a child]. One woman said, "When I am over 35, I think there will be various other risks with pregnancy and childbirth." (Woman 4). Participants said they wanted to give birth at as young an age as possible, and they thought $<$ There is a suitable age or time for childbirth $>$. Conversely, some women thought $<$ There is no suitable age or time for childbirth>, because they may not be able to decide to have a child merely by their own will. One woman said, "I leave it to our god. I think the baby will come to us when the timing is right." (Woman 5).

\section{2) Anxiety about forming a new family}

This category consisted of four subcategories: [Anxiety about raising their child], [Anxiety over whether they can make a new family], [Worry about a child who has a different nationality and background], and [They do not have any obvious anxiety]. [Anxiety about raising their child] consisted of four codes, 
one of which is $<$ Finances $>$. South Korean men spoke particularly strongly about this. One South Korean man said, "If the child wants to do something, but can't because of finances, this is truly bad." (Man 3). [Worry about a child who has a different nationality and background] consisted of <Child's nationality $>$ and $<$ Lack of understanding $>$. One woman said, "I don't understand the conditions concerning my child's nationality if I marry a zainichi partner. I haven't studied up on this enough." (Woman 1).

\section{3) Desire for a certain number and sex of children}

This category consisted of two subcategories: [They want to have a few children] and [Thinking about child's sex]. All participants, $<$ Desire one to three children>, and many had particular hope for two children. Moreover, many participants expressed $<$ Desire for a boy and a girl $>$, and notably $<$ Greater desire for a girl>.

\subsubsection{Work-Life Balance}

Two categories were highlighted from the four subcategories classified. There was consideration of Continuation of work after marriage and childbirth. Conversely, there was also a Possibility to stop working for a period after marriage and childbirth.

1) Continuation of work after marriage and childbirth

This category consisted of two subcategories: [Desire to continuation of work] and [Various styles of work]. Men thought about $<$ Wanting the woman to continue working $>$ after marriage and childbirth. Women also thought about $<$ Wanting to continue working $>$. One woman said, "I can take maternity leave and childcare leave at my office. If I get married and have a baby, it doesn't mean I have to quit my job, so I want to continue working after using the leave." (Woman 5).

2) Possibility to stop working for a period after marriage and childbirth

This category consisted of two subcategories: [They want to concentrate on childrearing when their child is young] and [They will consult with their partner and decide]. One woman said, "Even though my child would be so young, he or she would have to go to nursery school. This makes me feel miserable." (Woman 5). One man said, "I want to help with the housework as much as possible, but it's difficult because of my work." (Man 5). Although men thought about $<$ Helping a partner with childcare and housework $>$, they expressed that their work made this difficult. That was seen as a reason why some of them thought about $<$ Respect for partner's wishes $>$.

\subsubsection{Sexual Concerns}

Two categories were highlighted from four subcategories classified. They had Feelings about pregnancy as a reason for early marriage, and Feelings about declining birth rate and increase of marriages at a later age.

1) Feelings about pregnancy as a reason for early marriage

This category consisted of two subcategories: [They only think negatively] and [Getting married because of pregnancy can be challenging]. One man said, " $I$ 
have negative feelings about choosing to get married because of pregnancy." (Man 2). On the other hand, there were some opinions such as, [Getting married because of pregnancy can be challenging]. One woman said, "Marriage as a result of pregnancy is not so bad, because many people are infertile and cannot even get pregnant." (Woman 5).

2) Feelings about declining birth rate and increase of marriages at a later age

This category consisted of two subcategories: [Thinking about actual social phenomena] and [Thinking about the reasons]. The participants thought $<$ Declining birth rate and increasing of late time marriage cannot be helped $>$, and $<$ Neither the declining birthrate nor the increasing amount of marriages at a later age are bad $>$. One man said, "I never consider that choosing to get married at a later age is bad." (Man 3 ).

\section{Discussion}

This study demonstrated that couples consisting of a mix of Japanese, South Korean nationals, and zainichi had positive feelings toward marriage and new family planning, and anxiety related to their Confucian values and different nationalities/backgrounds. Furthermore, there is a possibility that gender roles or Confucianism-based traditional values affect sexual health, such as when stopping work after childbirth.

Recently, the mean ages of first marriage for women and for men, and first childbirth for women, in both Japan and South Korea are increasing: 29.3, 30.9, and 30.4 years, respectively, for Japan [5], and 30.0, 32.6, and 30.7 years [9] for South Korea. According to the Ministry of Health, Labour and Welfare of Japan [10], $10.6 \%$ of women and $20.1 \%$ of men in Japan as of 2010 would never marry. In South Korea, it was reported that younger people of marriageable age had felt indifferent about planning new families [11]. The participants of this study typically had a Positive feeling toward marriage, and thought about the Appropriate age or time for childbirth. However, they had some anxieties, such as [Anxiety about being inexperienced], [Anxiety about the future], and [Anxiety about raising their child]. Such anxieties have also been shown in earlier studies [12] [13] [14]. In this study, South Korean men in particular spoke strongly about $<$ Anxiety about finances $>$. It seems evident that finances are important for them when considering marriage [15], and outweigh emotional satisfaction.

Some women in this study wanted Continuation of work after marriage and childbirth and [Various styles of work]. However, they also had the following desire: [I want to concentrate on childrearing when my child is young]. The men wanted the following, $<$ Helping partner with childcare and housework $>$, yet they maintained the value that men should work outside and woman should perform housework. This suggests that the couples still had strong gender role considerations. According to the Organization for Economic Co-operation and Development [16], the rate of female labor force participation by age group in Japan and South Korea showed an M-shaped curve [17]. This indicated that the labor force contribution of women in their 20s and 30s slowed because of Confucianism- 
based traditional values [18]. Beliefs about of gender roles that are based on Confucian values may contribute to the disturbance of women's sexual health, such as in discontinuation of work.

Participants felt negatively toward pregnancy before marriage. Several reports have shown that approximately $25 \%$ of people became pregnant before marriage in Japan and South Korea [5] [6]. However study participants recognized the need for family planning based on Confucian values. Thus, it is essential for health professionals to provide appropriate knowledge and skills about family planning and child rearing, as well as premarital sexual health counselling, to couples composed of a mix of Japanese, South Korean nationals, and zainichi.

Many of the participants spoke about problems regarding [Anxiety about nationality and background] and [Disadvantage of different nationality and background]. They had a [Disadvantage] such as different cultures, customs, or not clearly understanding the legal standing of foreign residents in Japan. The participants with a zainichi partner spoke about [Worry about a child who has different nationality and background], while those with a South Korean partner spoke about [Anxiety about the future] and [Disadvantage of different nationality and background]. Zainichi Koreans are technically considered Korean nationals, but have primarily resided in Japan since birth. Therefore participants with a zainichi partner would experience little change in living conditions after marriage and childbirth, and have less concern about visiting parents, as all the parents typically also live in Japan. However, those marrying a South Korean partner worry about whether they will live and work in Japan or Korea. For these reasons participants with a South Korean partner tended to express [Disadvantage] in their narratives. Thus, there were differences in [Anxiety about nationality and background] among the different combinations of couples.

The number of foreigners in Japan continues to rise [1], as does the rate of international marriages [3]. Problems in international marriage are seen in the form of intercultural conflicts, domestic violence, and a high divorce rate [19]. It was reported that the satisfaction rate in couples who did not have language communication problems was significantly higher than that in couples who had communication problems [19] [20]. In this study, nobody spoke about language barriers, however, they felt [Disadvantage of different nationality and background], and [Worry about a child who has a different nationality and background]. Couples made up of a mix of Japanese, South Korean nationals, and zainichi felt [Disadvantage of different nationality and background]. Interestingly they also felt [Advantage of different nationality and background], in knowing different languages and cultures. Understanding of differences concerning these languages and cultures among the couples can help toward greater multicultural harmony in society.

Our study had a limitation in that the sample size is small. However this is the first report to demonstrate the current situations of sexual health in unmarried couples composed of Japanese, South Korean nationals, and zainichi. Further study will be necessary to evaluate sexual behavior and its related factors in un- 
married couples among these groups by means of quantitative study.

The couples we studied showed positive thought about marriage and family planning, while they had several sources of anxiety concerning Confucian values and problems as a result of different nationalities/backgrounds. Gender roles and Confucianism may have an impact on their sexual health. We clarified that health professionals need to provide knowledge and skills about family planning and child rearing, as well as premarital sexual health counselling, for unmarried couples composed of a mix of Japanese, South Korean nationals, and zainichi.

\section{Acknowledgements}

This work was supported by Japan Society for the Promotion of Science (JSPS) KAKENHI Grant Number 26861935.

\section{References}

[1] Ministry of Justice Statistics (2016) Annual Reports of Statistics on Registration of Foreign Residents: e-Stat in Jun.

http://www.e-stat.go.jp/SG1/estat/GL08020103.do?_toGL08020103_\&listID=000001 161643\&requestSender=estat

[2] Ministry of Justice Statistics (2016) The Central Organization of Japanese Statistics: The Estimate of Population Final Figure in October. www.stat.go.jp/data/jinsui/pdf/201610.pdf

[3] Santousha Editorial Department (2016) Data Collection of Woman's Life and Consideration of Living 2016. Santousha Inc., Tokyo.

[4] Japan Economic Newspapers (2015) The First Marriage and the First Childbirth Age Are Increasing Four Years in This 30 Years. http://www.nikkei.com/article/DGXLASFS22H0O_S5A620C1EAF000/

[5] Ministry of Health, Labor and Welfare (2010) Statistics about Birth in 2010: Special Report of Dynamic Trends in Population Statistics. http://www.mhlw.go.jp/toukei/saikin/hw/jinkou/tokusyu/syussyo06/index.html

[6] Chosun Newspapers (2013) One-Thirds of Newly Married Couples Are Getting Pregnant an Early Marriage: A Marriage Influenced by Unplanned Pregnant. http://news.chosun.com/site/data/html_dir/2013/06/26/2013062601073.htm

[7] Tsubaki, C., Machiura, M. and Saho, M. (2012)The Conditions of Sex Education, Sex Knowledge, Traditional Values and the Relations to Sex Behaviors among Korean College Students Living in Japan. Maternal Health, 4, 522-528.

[8] Kawakita, J. (1967) Conception. Chuokoron-Shinsha Inc., Tokyo.

[9] Korea Statistics Agency (2015) Statistics of Marriage and Divorce in 2015. http://kostat.go.kr/portal/korea/kor_nw/2/2/1/index.board?bmode=read\&aSeq=352 $\underline{513}$

[10] Ministry of Health, Labor and Welfare (2014) Health Preventive First Year: The Transition about Percentage of Unmarried People during Whole Life. http://www.mhlw.go.jp/wp/hakusyo/kousei/14/backdata/2-1-1-02.html

[11] Korea Statistics Agency (2014) Analysis of Main Characteristics According to a Life Period. http://kostat.go.kr/portal/korea/kor_nw/3/index.board?bmode=read\&aSeq=332089

[12] Yamamoto, K., Kameya, F., Kajita, H., Nishitani, Y., Tsuchiyama, A., Higashi, M., Sumiya, Y., Toyama, M., Kiyohara, M., Shiraishi, M., Wada, N. and Otani, T. (2015) 
The Attitude Survey of Work Life Balance in Nursing Department. Journal of Kobe Century Memorial Hospital, 28, 5-11.

[13] Hira, S. and Sanpei, M. (2016) Psychological Support for Primiparous Single Mothers in Their Pregnancy: Compared with the Psychology of the Group of the Primiparous Married Women. Maternal Health, 4, 642-651.

[14] Suzuki, S. and Wada, Y. (2010) The Factors Influencing the Ideal and Intended Number of Children Considered for Japanese Mothers. Bulletin of Health Science University, 6, 93-103.

[15] Chuou Nippou (2015) Let's Defend 50 Million People at Korea: Misfortune of Low Birth (2)-The Condition of Unmarried People and Birth Plan of the Married People. http://japanese.joins.com/article/774/209774.html

[16] Organization for Economic Cooperation and Development (OECD). Stat (2016) Labour Force Statistics by Sex and Age-Indicators: Labour Force Participation. https://stats.oecd.org/Index.aspx?DataSetCode=LFS_SEXAGE_I_R

[17] Komase, Y. (2014) The Aims of Gender Equal Society. The Journal of St. Marianna University School of Medicine, 42, 45-52.

[18] Japan Economic Newspapers (2016) The Problems in a Super-Falling Birthrate Should Be Caused of Gender Division: An Attitude Survey of Japan and Korea. http://www.nikkei.com/article/DGKKZO02861440X20C16A5M10600/

[19] Takeshita, S. (2001) Cultural Adjustment and Marital Satisfaction of International Couples: The Cases of Taiwanese Husbands and Japanese Wives in Taiwan. The Journal of Kinjo Gakuin University of Social Science, 44, 127-137.

[20] Qu, X. (2009) The Research Movement and Perspective of International Marriages in Japan. Bulletin of the University of Tokyo Graduate School Education Research Course, 49, 265-275.

\section{Submit or recommend next manuscript to SCIRP and we will provide best} service for you:

Accepting pre-submission inquiries through Email, Facebook, LinkedIn, Twitter, etc. A wide selection of journals (inclusive of 9 subjects, more than 200 journals)

Providing 24-hour high-quality service

User-friendly online submission system

Fair and swift peer-review system

Efficient typesetting and proofreading procedure

Display of the result of downloads and visits, as well as the number of cited articles

Maximum dissemination of your research work

Submit your manuscript at: http://papersubmission.scirp.org/

Or contact health@scirp.org 